OPEN ACCESS

Edited by:

Jun-Lin Yi,

Chinese Academy of Medical Sciences and Peking Union Medical

College, China

Reviewed by:

Michael Andrew Samuels,

University of Miami, United States

Elvio G. Russi,

Azienda Sanitaria Ospedaliera

S. Croce e Carle Cuneo, Italy

*Correspondence:

Lihua Dong

419522637@qq.com

Xin Jiang

jiangx@jlu.edu.cn

Specialty section:

This article was submitted to Radiation Oncology,

a section of the journal

Frontiers in Oncology

Received: 16 December 2020 Accepted: 23 February 2021

Published: 18 March 2021

Citation:

Liu S, Zhao Q, Zheng Z, Liu Z, Meng L, Dong $L$ and Jiang $X$ (2021) Status of Treatment and Prophylaxis for Radiation-Induced Oral Mucositis in Patients With Head and Neck Cancer. Front. Oncol. 11:642575. doi: 10.3389/fonc.2021.642575

\section{Status of Treatment and Prophylaxis for Radiation-Induced Oral Mucositis in Patients With Head and Neck Cancer}

\author{
Shiyu Liu ${ }^{1,2,3}$, Qin Zhao 1,2,3, Zhuangzhuang Zheng ${ }^{1,2,3}$, Zijing Liu 1,2,3, Lingbin Meng ${ }^{4}$, \\ Lihua Dong ${ }^{1,2,3 *}$ and Xin Jiang ${ }^{1,2,3 *}$ \\ ${ }^{1}$ Department of Radiation Oncology, The First Hospital of Jilin University, Changchun, China, ${ }^{2}$ Jilin Provincial Key Laboratory \\ of Radiation Oncology \& Therapy, The First Hospital of Jilin University, Changchun, China, ${ }^{3}$ National Health Commission \\ (NHC) Key Laboratory of Radiobiology, School of Public Health, Jilin University, Changchun, China, ${ }^{4}$ Department of \\ Hematology and Medical Oncology, Moffitt Cancer Center, Tampa, FL, United States
}

Radiation-induced oral mucositis (RIOM) is one of the most frequent complications in head and neck cancer ( $H N C$ ) patients undergoing radiotherapy $(R T)$. It is a type of mucosal injury associated with severe pain, dysphagia, and other symptoms, which leads to the interruption of RT and other treatments. Factors affecting RIOM include individual characteristics of HNC patients, concurrent chemoradiation therapy, and RT regimen, among others. The pathogenesis of RIOM is not yet fully understood; however, the release of inflammatory transmitters plays an important role in the occurrence and development of RIOM. The five biological stages, including initiation, primary damage response, signal amplification, ulceration, and healing, are widely used to describe the pathophysiology of RIOM. Moreover, RIOM has a dismal outcome with limited treatment options. This review will discuss the epidemiology, pathogenesis, clinical appearance, symptomatic treatments, and preventive measures related to this disease. We hope to provide a reference for the clinical treatment and prevention of RIOM in HNC patients after RT.

Keywords: radiotherapy, oral mucositis, epidemiology, pathogenesis, treatment, prevention

\section{INTRODUCTION}

Head and neck cancer (HNC) is a common type of neoplasm, including neck tumors, otolaryngology tumors, and oral-maxillofacial tumors, such as nasopharyngeal, oropharyngeal, hypopharyngeal, and laryngeal cancers. In recent years, radiotherapy (RT) has become increasingly popular as a treatment for HNC patients. RT techniques include intensity-modulated radiotherapy (IMRT), stereotactic body radiation therapy, particle therapy, and high-dose-rate brachytherapy (1). The typical radiation regimen for HNC patients comprises a dose of 2 Gy per day for 5-7 continuous weeks, with a total cumulative dose of 60-70 Gy (2). Due to the relationship between the primary site of HNC and the occurrence of cervical lymph node metastasis, the oral mucosa inevitably accounts for a part or all of the target area in HNC patients undergoing RT; thus, it is exposed to a certain dose of irradiation. Radiation-induced oral mucositis (RIOM) represents a major complication in HNC patients undergoing RT, occurring in almost all patients treated for cancers of the mouth, oropharynx, and nasopharynx. RIOM is an inflammatory or ulcerative lesion 
caused by radiation-induced damage to basal cells rather than direct damage to superficial cells (3). In this review, we will discuss some recent topics dealing with the epidemiology, mechanisms, and clinical manifestations of RIOM and various approaches for the prevention and treatment of mucositis related to RT.

\section{RIOM EPIDEMIOLOGY Influence Factor of RIOM}

RIOM is found in virtually all HNC patients who undergo RT, with the incidence exceeding $90 \%$ in patients treated with standard regimens (4). A study has shown that HNC patients with nasopharyngeal or oropharyngeal tumors and those who receive cumulative radiation doses $>5000$ cGy or concurrent chemoradiation therapy (CCRT) are more likely to develop RIOM (5).

\section{Self-Related Factors in HNC Patients}

Several patient-related factors, such as age, weight, sex, nutritional status, oral microbiota, and oral health status, have been identified as risk factors associated with RIOM development $(6,7)$. Poor oral health habits, smoking, and malnutrition all result in an increased incidence of RIOM (5).

\section{Chemotherapy}

The incidence of RIOM increases with the use of concurrent chemotherapy. HNC patients with CCRT present improved local tumor control at the expense of increased risk of RIOM. Chen et al. (8) explored the changes in the prevalence of severe RIOM and RIOM-related symptoms over an 8-week period. Their findings showed that HNC patients had a higher prevalence of RIOM when treated with combined RT and chemotherapy than when treated with RT alone. Elting et al. (4) reported that RIOM was more common in patients receiving chemotherapy combined with IMRT $(\mathrm{OR}=7.8)$ than in patients receiving IMRT alone. A phase 3 multicenter randomized controlled trial (NCT00677118) evaluated the efficacy of adjuvant chemotherapy. In this study, during CCRT, $31 \%$ of patients in the CCRT plus adjuvant chemotherapy group developed RIOM. Noticeably, $21 \%$ of patients developed RIOM during the adjuvant chemotherapy period (9). In summary, these studies showed that chemotherapy increased the incidence of RIOM.

Abbreviations: SCCRT, concurrent chemoradiation therapy; CTCAE, Common Terminology Criteria for Adverse Events; GM-CSF, granulocyte macrophagecolony stimulating factor; HNC, head and neck cancer; IL-1 $\beta$, Interleukin- $1 \beta$; IL-6, Interleukin-6; IMRT, intensity-modulated RT; LEL, low-energy heliumneon laser; L-GLN, L-glutamine; LLLT, low-level laser therapy; MASCC/ISOO, Multinational Association of Supportive Care in Cancer and International Society of Oral Oncology; MMP, matrix metalloproteinase; NCI-CTC, National Cancer institute Common Toxicity Criteria; PBRT, proton beam radiation therapy; PEG, percutaneous endoscopic gastrostomy; RIOM, Radiation-induced oral mucositis; RT, radiotherapy; RTOG, Radiation Therapy Oncology Group; SBRT, stereotactic body radiation therapy; TNF- $\alpha$, tumor necrosis factor- $\alpha$; VMAT, volumetric modulated arc therapy; WCCNR, Western Consortium for Cancer Nursing Research; WHO, World Health Organization.

\section{Radiotherapy Regimen}

Changes in the dose fractionation protocol and difference in RT techniques result in different incidences of RIOM. Trotti et al. (10) reported a trend for high incidence of Grade III or higher mucositis. In a study of HNC patients treated with altered fractionation RT $(1.25-2.00 \mathrm{~Gy} / \mathrm{f})$ found that $56 \%$ of patients experienced RIOM (Grade III-IV) compared to $34 \%$ of patients who received conventional RT. Hsiung et al. (11) evaluated the radiation dose supplied to the oral mucosa during IMRT for HNC and reported that IMRT can reduce the severity of RIOM compared to conventional RT. Romesser et al. (12) randomly assigned $23 \mathrm{HNC}$ patients to be treated with IMRT and 18 HNC patients to be treated with proton beam radiation therapy (PBRT). This study demonstrated that the incidence of RIOM after PBRT was significantly lower than that after IMRT (16.7 vs. $52.2 \%)$.

The dose of RT is another factor that affects RIOM. Radiation causes necrosis of the epithelium, leading to desquamation and ulceration. And with the increasing irradiation dose, the more severe of the degree of RIOM. A cumulative radiation dose $\geq 50 \mathrm{~Gy}$ is found to increase the risk of RIOM; when the cumulative radiation dose is $\geq 65 \mathrm{~Gy}$, the risk of RIOM in HNC patients is the highest (5). Narayan et al. (13) conducted a clinical trial to correlate oral cavity dose with RIOM. And they found that the cumulative point doses $<32$ Gy occurred mild severity (Grade $</=1$ ) and short duration $(</=1$ week) of mucositis. They also concluded that a dose $>39$ Gy was associated with longer duration of mucositis. In a conclusion, limiting dose to $<39$ Gy or an average oral mucosa dose $<32$ Gy resulted in mild severity and only a short duration of RIOM for HNC patients. Based on this conclusion, Wang et al. (14) made a prospective and comparative trial to observe the incidence of RIOM for HNC patients $(n=24)$ received $<32 \mathrm{~Gy}$. And they found that just $25 \%$ of HNC patients suffered Grade III RIOM, and they rarely use analgesics and intravenous antibiotics.

\section{Cetuximab}

Comprehensive treatment other than chemotherapy combined with RT may affect RIOM. In the current study, a high incidence of Grade III-IV RIOM was observed in HNC patients receiving RT combined with cetuximab (15). In another study, compared to CCRT alone, adding cetuximab resulted in a reduction in Grade III-IV RIOM incidence (51.6 vs. $23.4 \%$; $P<0.001$ ) (16). But some researches detected that cetuximab combinded with RT does not have a significant impact on the incidence of high-grade ( $\geq$ grade 3 ) mucositis in comparison to RT alone $(17,18)$. Bonner et al. (19) had made a phase III randomized trial, HNC patients were randomly assigned to receive RT with or without cetuximab. Five-year overall survival was $45.6 \%$ in the cetuximab-plus-RT group and $36.4 \%$ in the RT group. However, the incidence of RIOM (93.3 vs. 93.9\%) was similar in both groups. In another research, Tejwani et al. (20) found that, when the combination of RT plus cetuximab was compared with radiation alone, the risk ratio for mucositis it was $1.76(95 \%$ CI, 1.5-2.0; $P<0.001$ ), suggesting that there was an increased risk of dermatologic toxicities with the combined regimen. Mei et al. (21) searched relevant articles to compare the efficacy of 
concurrent cetuximab with RT(ExRT) vs. cetuximab combined with RT and chemotherapy (ChRT) in treating HNC patients. And they deduced that cetuximab was an effective radiosensitizer, while ChRT achieved better survival outcomes than ExRT. Additionally, cetuximab combined with RT presented increasing occurrence of mucositis (RR: 1.17, $p<0.005$ ) in comparison to ChRT group.

\section{PATHOGENESIS}

The pathogenesis of RIOM includes both direct and indirect mechanisms. The direct effect is due to DNA strand breakage and apoptosis caused by radiation, resulting in a reduction in the renewal of the basal epithelium (22). The indirect effect is due to factors such as the release of inflammatory transmitters, secretion of salivary glands, and neutropenia, causing the destruction of the oral mucosa (23). At present, the five biological stages proposed by Sonis are widely used to describe the occurrence and development of RIOM (24). The five stages comprise initiation, primary damage response, signal amplification, ulceration, and healing.

\section{Initiation}

The initiation stage of oral mucosal injury occurs rapidly after the administration of radiation and involves DNA and non-DNA damage and the production of reactive oxygen species (ROS). RT directly damages the DNA, resulting in double-strand breaks and apoptosis of basal epithelial cells and submucosal cells. ROS are crucial mediators of downstream biological agents that are released from the epithelium and tissue macrophages. ROS generated by intracellular water ionization cause a series of damages to cells, leading to organelle damage. Mitochondria release additional ROS, which in turn damage cell membranes and connective tissue, stimulate macrophages, and activate molecules of the immunoinflammatory response. The inflammatory substances and pathways released include intracellular proinflammatory chemoradiation associated molecular patterns; intracellular enzymes (lysosomial), which activate extracellular proinflammatory damage associated molecular patterns; altered redox state of the injured tissue; presynthesised interleukins (IL-1 $\alpha$, IL-33); released intracellular hidden antigens which activate complement via antibodies (25). In addition, oxidative stress and ROS production can directly damage cells, tissues, and blood vessels and stimulate the production of a large number of transcription factors, such as NF-кB (26).

\section{Primary Damage Response}

Radiation leads to double-strand DNA breaks and activates many downstream signal transduction pathways. Song et al. (27) summarized fourteen pathways as being most relevant to the development of RIOM, including nitrogen metabolism; Toll-like receptor signaling; NF- $\kappa \mathrm{B}$ signaling; B Cell receptor signaling; P13K/AKT signaling; Cell Cycle: G2/M DNA Damage checkpoint receptor; P38 MAPK signaling; Wnt/B-catenin signaling; Glutamate receptor signaling; Integrin signaling; VEGF signaling; IL-6 signaling; Death receptor signaling;
SAPK/JNK signaling. A variety of transcription factors are activated, such as p53 and NF- $\kappa$ B. Among them, NF- $\kappa$ B has been suggested to be the most significant transcription factor, and it is related to both toxicity and resistance of tumors to therapy (28). The activation of NF-кB in the nucleus promotes the proliferation of proinflammatory factors, such as interleukin (IL)-1 $\beta$, IL-6, and tumor necrosis factor- $\alpha$ (TNF$\alpha)$. These compounds induce cell damage, leading to apoptosis (29). In addition, fibronectin breakdown occurs at this stage. Importantly, all of these changes occur in all cells and tissues that form the mucosa and not just those that form the epithelium.

\section{Signal Amplification}

Some of these proinflammatory cytokines not only damage tissue, but also provide a positive feedback loop to amplify the primary damage response induced by radiation. TNF- $\alpha$ is an efficient activator of NF- $\kappa \mathrm{B}$ and sphingomyelinase. TNF- $\alpha$ activates NF$\kappa \mathrm{B}$ and sphingomyelinase activity in the mucosa, leading to more cell death. TNF- $\alpha$ amplify the original signal or activate NF- $\mathrm{B}$, leading to the initiation of MAPK and COX-2 transcription. The MAPK pathway ultimately results in the activation of caspase 3 and cell death (30). The increased level of sphingomyelinase in the tissue amplifies pro-apoptotic signals that are mediated by the ceramide pathway, promoting the cell death. Both TNF$\alpha$ and IL-1 $\beta$ induce matrix metalloproteinase (MMP)-1 and MMP-3 activation, and COX-2 initiates and transmits signals that activate MMP-1 and MMP-3, leading to disruption of oral mucosal integrity (31). Many proteins produced during the primary injury response accumulate and target mucosal tissues acting both intracellularly and intercellularly, triggering feedback mechanisms via neuronal and blood flow networks, causing an increasing serum levels of NF- $\kappa$ B, TNF- $\alpha$, IL- 1 , and IL-6, which generated abscopal effects and toxicity (32). Abscopal effects and toxicity include sepsis causing systemic inflammatory responses, alterations in body temperature and metabolism, fatigue, and others (33).

\section{Ulceration}

During this period, the oral mucosa usually presents with a pseudomembrane or ulceration. This is due to damage to the mucosa. Nerve endings are exposed to the surface, resulting in pain and other symptoms. Microbial colonies appear on the mucosal surface, and cell wall products from the colonizing bacteria are likely to penetrate the submucosa, destroying any new tissue and increasing the release of inflammatory mediators from monocytes (34). This chain of events probably promotes the expression of pro-apoptotic genes and potentiates tissue injury. The pathogenetic characteristics of RIOM in HNC patients are depicted in Figure 1.

\section{Healing}

At this stage, epithelial cell proliferation and histiocyte differentiation can be seen, thereby restoring tissue integrity. Factors affecting the speed of mucosal repair include the rate of epithelial cell migration, rate of proliferation, differentiation of healing tissue, agents selected, and dose and timing of therapy. 


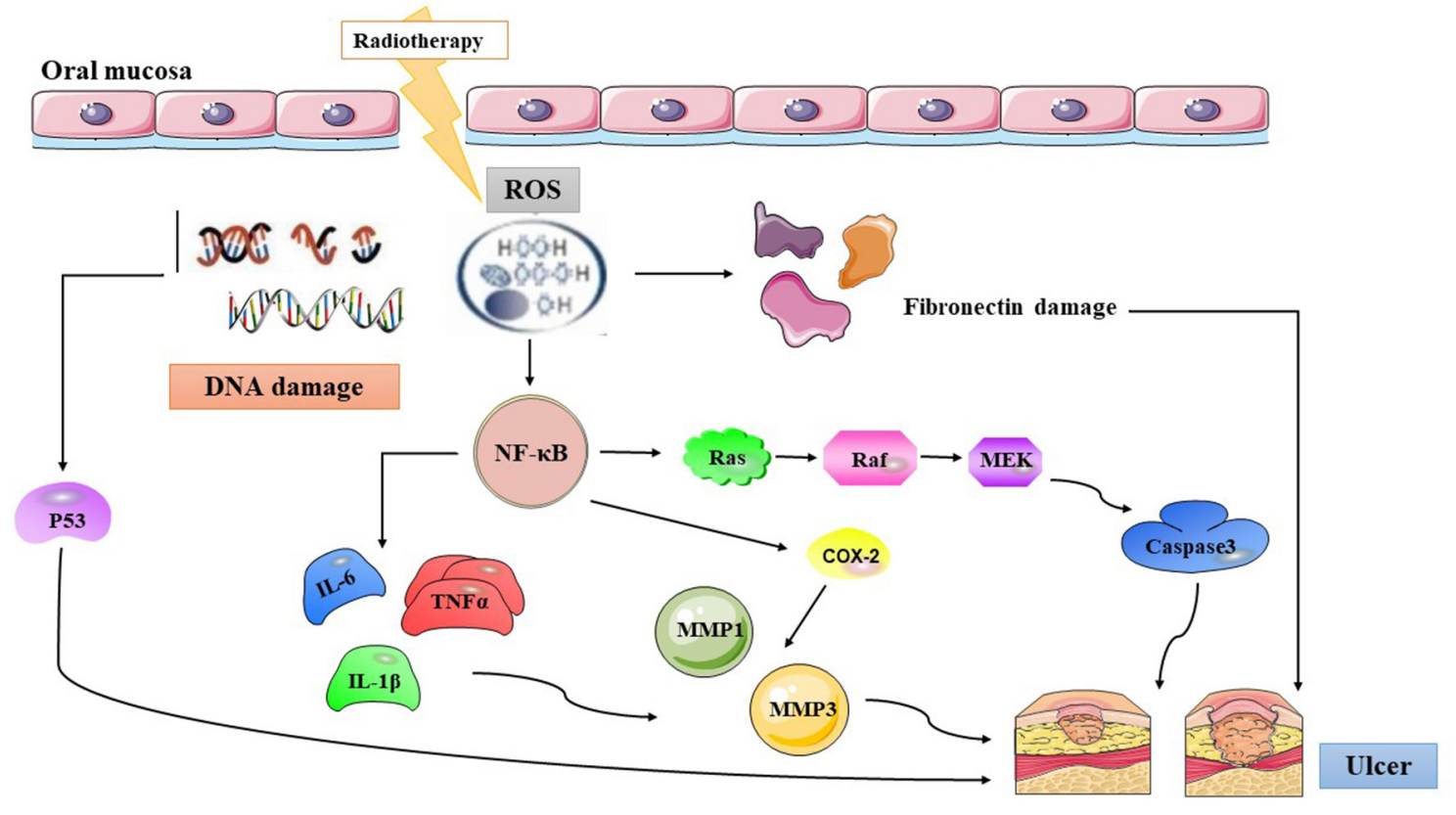

FIGURE 1 | The summary of radiation-induced oral mucositis pathogenesis. Radiotherapy results in direct and lethal DNA damage and releases reactive oxygen species (ROS) from epithelial and tissue macrophages in initiation phase. In primary damage phase, the DNA damage and ROS lead to three major steps: (1) fibronectin breakdown (2) P53 activation (3) nuclear factor-kB (NF-kB) activation that stimulates to release pro-inflammatory cytokines, such as: TNF- $\alpha$, interleukin (IL)-1 $\beta$, and IL-6. In the signal amplification phase, NF-KB stimulates the transcription of MAPK, COX-2, etc. The pathway of MAPK actives caspase3, and the other cytokines transmit signals that activate MMP1 and MMP3. Then the pseudomembrane or ulceration appear after around two weeks undergoing with symptomatic treatment of RIOM, and secondary infection adds more pro-inflammatory reactions. ROS, Reactive Oxygen Species; NF- $\kappa B$, Nuclear factor kappa-B; IL-6,

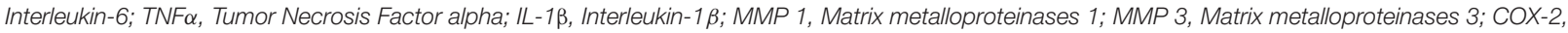
Cyclooxegenase-2.

\section{CLINICAL APPEARANCE}

RIOM usually appears 2.5 weeks after RT initiation and continues for 2-3 weeks after treatment completion. Clinically, RIOM is characterized by pain in the oropharynx, dysphagia, language disorders, and nutritional deterioration. Currently, the Radiation Therapy Oncology Group (RTOG) grading is widely used to evaluate the severity of RIOM: Grade I: erythema and mild painful mucositis requiring no analgesics; Grade II: patchy mucositis requiring analgesics; Grade III: confluent mucositis and severe pain requiring narcotic analgesics; and Grade IV: deep ulcerations and/or necrosis (and sometimes bleeding), with extreme pain, and patients cannot eat anymore. Specific examples of different grades of mucositis are shown in Figure 2. A 1020 Gy dose provokes hyperkeratosis of the oral mucosa, an initial clinical sign accompanied by pain and functional impairment by the 2 nd week of treatment (35). At this point, the first signs of erythema are seen. Subsequently, in the third week, once HNC patients have received a dose of more than $20 \mathrm{~Gy}$, they present with a mild and unnoticeable focal area of desquamation (36). In the 4th week, when HNC patients have received more than $30 \mathrm{~Gy}$, diffuse mucosal ulceration appears. Ulcerative lesions are often covered by a pseudomembrane composed of fibrinous exudates and dead cells (37). Many scales can be used to evaluate the severity of mucositis, such as the RTOG scale, World Health Organization oral toxicity scale, Common
Terminology Criteria for Adverse Events scale, National Cancer Institute Common Toxicity Criteria (NCI-CTC), and Western Consortium for Cancer Nursing Research stomatitis staging system (Table 1) (38-40).

\section{SYMPTOMATIC TREATMENT OF RIOM}

The treatment of RIOM is essentially symptomatic, with treatment of complicated infections, and promotion of wound healing of the oral mucosa. If the patient develops severe RIOM, the suspension of RT may be required. The Multinational Association of Supportive Care in Cancer and International Society of Oral Oncology (MASCC/ISOO) Clinical Practice Guidelines are commonly used in the treatment of RIOM (41).

\section{Pain Management}

Pain is the most common symptom among patients with RIOM. Evaluating oral pain is necessary for every patient, and the treatment regime is determined by the level of pain reported by the patients. When RIOM is accompanied by mild pain, acetaminophen and lidocaine can be applied. Acetaminophen with codeine suspension can be used for moderate pain and strong opioids such as morphine or fentanyl need to be used when mucositis progresses to cause severe pain (42). A morphine mouthwash $(0.2 \%)$ may be effective in treating pain due to RIOM to reduce the need for systemic morphine (39). 


\section{Medications}

\section{Cytokines and Growth Factors}

The destruction of the integrity of oral epithelial cells and the decline in the ability of mucosal repair are major features of RIOM. Many growth factors and cytokines are used clinically to promote mucosal repair and healing in RIOM.

Kannan et al. (43) administered granulocyte macrophagecolony stimulating factor (GM-CSF) to $10 \mathrm{HNC}$ patients. GMCSF was administered subcutaneously at a dose of $1 \mu \mathrm{g} / \mathrm{kg}$ daily, after a dose of $20 \mathrm{~Gy}$ and until the completion of RT. They observed that GM-CSF was able to protect the oral mucosa during RT.

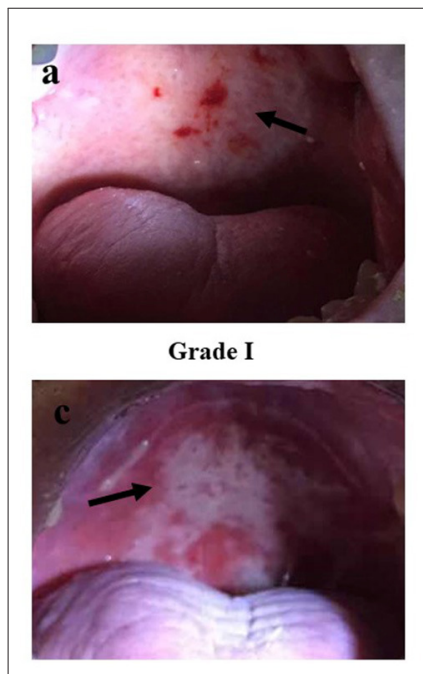

Grade III

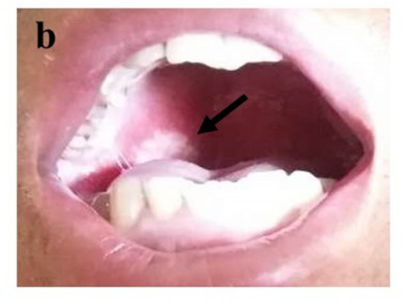

Grade II

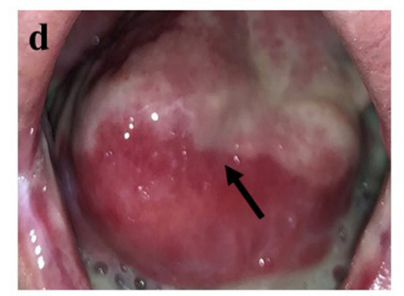

Grade IV
FIGURE 2 | The Radiation Therapy Oncology Group (RTOG) scoring criteria for radiation-induced oral mucositis. (a) Grade I: Erythema; (b) Grade II: Patchy reaction ( $<1.5 \mathrm{~cm}$, non-contiguous); (c) Grade III: Confluent mucositis (>1.5 cm, contiguous); (d) Grade IV: Ulceration, necrosis, bleeding. Republished with the permission of patients.
Keratinocyte growth factor (KGF) is a type of human embryonic lung fibroblast growth factor that enhances the regenerative capacity of epithelial tissues and protects them from various toxic agents. Palifermin is an $\mathrm{N}$-terminal, truncated version of KGF. Henke et al. (44) conducted a multicenter, placebo-controlled trial to observe the effect on palifermin in HNC patients suffering RIOM. Patients were randomly assigned to receive weekly palifermin $120 \mu \mathrm{g} / \mathrm{kg}$ or placebo from 3 days before and continuing throughout radiochemotherapy. And they demonstrated that palifermin decreased the duration of RIOM (median, 4.5 vs. 22.0 days) and prolonged the time to develop (median, 45 vs. 32 days) severe RIOM. Le et al. (45) reported a similar trial; HNC patients received palifermin (180 $\mu \mathrm{g} / \mathrm{kg}$ ) or placebo before starting chemoradiotherapy, once weekly for 7 weeks. The incidence of severe RIOM was significantly lower in the palifermin group than in the placebo group (54 vs. $69 \% ; P=0.041$ ).

Maria et al. (46) conducted a study in an animal model of RIOM, which implanted 5 doses of 2.5 million freshly cultured syngenic aMSCs intraperitoneally, to investigate the ability of mesenchymal stromal cells (MSCs) to repair RIOM. They found that MSCs reduced ulcer duration to $1.6 \pm 0.3$ days $(95 \% \mathrm{CI}$ $0.0233-3.1$ days, a $72 \%$ reduction in RIOM ulcer duration). This research initially confirmed the efficacy of MSCs in repairing RIOM, providing a novel treatment regime for RIOM.

Epidermal growth factor (EGF) enhances mucosal wound healing and tissue generation by regulating epithelial cell proliferation, growth, and migration. A placebo-controlled prospective clinical trial assigned HNC patients to a placebo group or to 1 of 3 EGF-treatment groups (10, 50, or 100 $\mathrm{microg} / \mathrm{mL}$ doses, delivered in a spray, twice daily). This research mainly observed the incidence of severe oral mucositis. Then it revealed that EGF significantly reduced the incidence of severe oral mucositis: $50 \mu \mathrm{g} / \mathrm{mL}$ EGF displayed a 64 response vs. $37 \%$ response in the control group $(P=0.0246)$. Therefore, EGF has potential benefits in the treatment of RIOM (47).

In summary, different cytokines or growth factors (KGF, GMCSF, EGF, and MSCs) affect different cell lines (keratinocytes,

TABLE 1 | Grading criteria.

\begin{tabular}{|c|c|c|c|c|}
\hline Grade & 1 & 2 & 3 & 4 \\
\hline RTOG & Erythema & $\begin{array}{l}\text { Patchy reaction ( }<1.5 \mathrm{~cm} \text {, } \\
\text { non-contiguous) }\end{array}$ & $\begin{array}{l}\text { Confluent mucositis (>1.5 cm, } \\
\text { contiguous) }\end{array}$ & Ulceration, necrosis, bleeding \\
\hline WHO & $\begin{array}{l}\text { Sore throat } \pm \text { erythema, able to eat } \\
\text { solid food }\end{array}$ & $\begin{array}{l}\text { Ulcers } \pm \text { erythema, able to eat solid } \\
\text { food }\end{array}$ & $\begin{array}{l}\text { Ulcers with extensive erythema, } \\
\text { requires liquid diet }\end{array}$ & alimentation not possible \\
\hline CTCAE v5.0 & $\begin{array}{l}\text { Asymptomatic or mild symptoms; } \\
\text { intervention not indicated }\end{array}$ & $\begin{array}{l}\text { Moderate pain; not interfering with } \\
\text { oral intake; modified diet indicated }\end{array}$ & $\begin{array}{l}\text { Severe pain; interfering with oral } \\
\text { intake }\end{array}$ & $\begin{array}{l}\text { Life-threatening consequences; } \\
\text { urgent intervention indicated }\end{array}$ \\
\hline $\mathrm{NCl}-\mathrm{CTC}$ & Erythema of the mucosa & $\begin{array}{l}\text { Patchy pseudomembranous } \\
\text { reaction (patches generally } \leq 1.5 \mathrm{~cm} \\
\text { in diameter and non-contiguous) }\end{array}$ & $\begin{array}{l}\text { Confluent pseudomembranous } \\
\text { reaction (contiguous patches } \\
\text { generally }>1.5 \mathrm{~cm} \text { in diameter) }\end{array}$ & $\begin{array}{l}\text { Necrosis or deep ulceration; may } \\
\text { include bleeding not induced by } \\
\text { minor trauma or abrasion }\end{array}$ \\
\hline WCCNR & $\begin{array}{l}\text { Lesions: none } \\
\text { Color: pink } \\
\text { Bleeding: none }\end{array}$ & $\begin{array}{l}\text { Lesions: } 1-4 \\
\text { Color: slight red } \\
\text { Bleeding: none }\end{array}$ & $\begin{array}{l}\text { Lesions: more than } 4 \\
\text { Color: moderately red } \\
\text { Bleeding: with eating and hygiene }\end{array}$ & $\begin{array}{l}\text { Lesions: coalescing } \\
\text { Color: very red } \\
\text { Bleeding: spontaneous }\end{array}$ \\
\hline
\end{tabular}

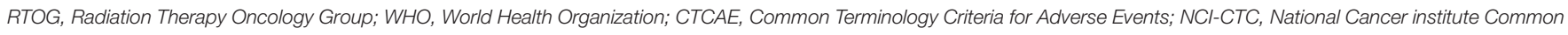
Toxicity Criteria; WCCNR, Western Consortium for Cancer Nursing Research. 
macrophages, and fibroblasts), and thus, they promote the healing of the oral mucosa.

\section{Anti-inflammatory Agents}

RIOM represents an interaction of oral mucosal cells and tissues, proinflammatory cytokines (IL-11, IL-1, and IL-6), and local factors. Benzydamine is a non-steroidal drug that has shown topical anti-inflammatory, analgesic, anesthetic, and antimicrobial activities and can be used to treat RIOM in patients with HNC. Epstein et al. (48) and Sheibani et al. (49) evaluated the efficacy of benzydamine in the treatment of RIOM. Subjects were rinsed with $15 \mathrm{ml}$ benzydamine or placebo daily for 2 min, 4-8 times, before and during radiotherapy and 2 weeks after radiotherapy. Epstein et al. found that phenethylamine significantly $(P=0.006)$ reduced erythema and ulcers by about $30 \%$ compared with placebo. Sheibani et al. found that RIOM over grade 3 occurred later in the benzydamine group than in the placebo group.

A multicenter, randomized clinical trial revealed that, when RIOM appeared, $0.1 \%$ steroid ointment softens with olive oil was applied to the oral mucosa four times per day, after meals and before bedtime, which can decrease the incidence of grade III RIOM (50). Topically administered corticosteroids have been widely used in the treatment of RIOM, as they can reduce edema, inhibit inflammation, and alleviate symptoms of patients, but the long-term administration of topical steroids may promote candidiasis (51).

Rebamipide is an agent that inhibits the production of inflammatory cytokines, such as IL-1, IL-8, and TNF- $\alpha$, and may even have anti-ROS effects (52). Yasuda et al. (53) assessed the efficacy and safety of rebamipide in treating RIOM. This gargle solution, at $300 \mathrm{~mL}$ per bottle for 1 day, was used in 6 divided doses. The number of patients with severe mucositis ( $\geq$ grade 3 RIOM) was higher in the placebo group than in the rebamipide group (83.3 vs. $33.3 \%, P=0.036$ ), which clearly indicates the contribution of rebamipide in decreasing the severity of oral mucositis.

In addition, honey also has anti-inflammatory effects and can promote wound healing. Khanal et al. (54) conducted a single-blinded, randomized, controlled clinical trial to compare the mucositis-limiting qualities of honey with lignocaine. Each patient would receive an intervention, including $20 \mathrm{ml}$ of either honey or lignocaine gel that would have to be swished about the oral cavity for $2 \mathrm{~min}$ and expectorated, for $15 \mathrm{~min}$ prior to radiation, $15 \mathrm{~min}$ after radiation and once before going to bed. Only 1 of 20 patients in the honey group developed $\geq$ grade III RIOM compared with the lignocaine group, which is 15 of 20 patients. They indicated that honey had a strong protective effect against the development of mucositis.

\section{Antimicrobial Agent}

RIOM may become infected and require antibiotic therapy. Oral mucosal swabs should be sent for bacterial and fungal culture and drug susceptibility tests to guide the use of antimicrobial agents before treatment (55). Chlorhexidine gluconate is widely recognized as an antimicrobial agent that helps avoid plaque development and control early periodontal infections (56).
Stokman et al. (57) observed that the colonization index of Candida and gram-negative bacilli decreased in patients who received active $1 \mathrm{~g}$ lozenges containing polymyxin $\mathrm{E}(2 \mathrm{mg})$, tobramycin $(1.8 \mathrm{mg})$, and amphotericin B (10 mg) at four times daily during the full course of RT. Therefore, this is an effective way to prevent and treat infections in RIOM.

\section{Oral Mucosal Protectant}

Misoprostol is a synthetic analog of prostaglandin E1 with antiinflammatory and mucosa-protecting properties. Veness et al. (58) designed a randomized, double-blind, placebo-controlled trial of misoprostol in patients, but this study was not able to identify a reduction in RIOM in patients receiving misoprostol.

Amifostine has the potential to enable intensified treatment by ameliorating mucosal destruction, but it does not reduce antitumor efficacy. Bourhis et al. (59) conducted a clinical trial, the HNC patients were randomized to receive or not $150 \mathrm{mg} / \mathrm{m}$ (2) amifostine, 15-30 min prior to each radiation session. And they found that only 1 patient treated with amifostine developed Grade IV mucositis, compared to 8 patients treated without amifostine. They also suggested that amifostine can reduce the severity and duration of RIOM. Similarly, Veerasarn et al. (60) observed the efficacy of amifostine in the treatment of RIOM and found that amifostine significantly reduced the incidence of grade $\geq 2$ mucositis from 75 to $36 \%$. However, another phase III trial concluded that injecting amifostine every day may result in a high rate of serious adverse effects, leading to the discontinuation of amifostine treatment and sometimes a delay in RT (61).

Receiving oral L-glutamine (L-Gln) is another treatment option for RIOM. A trend toward a beneficial effect on the severity of RIOM was suggested by Huang et al. (62). In a study of 17 HNC patients treated for RIOM with glutamine suspension ( $16 \mathrm{~g}$ glutamine in $240 \mathrm{ml}$ normal saline) or normal saline, all of them received half-mouth irradiation at least. Then, they evaluated the grade of RIOM until $45 \mathrm{~Gy} / 25$ fractions, and found that the duration of RIOM $\geq$ Grade $1(p=0.0097)$, Grade $2(p=0.0232)$, and Grade $3(p=0.0168)$ was shorter in the glutamine arm. they concluded that oral glutamine may shorten the duration and severity of grade III mucositis.

\section{Low-Level Laser Therapy (LLLT)}

LLLT is one of the most recent and promising treatment approaches for RION. MASCC/ISOO recommends LLLT for oral mucositis in HNC patients receiving RT (41). LLLT promotes the proliferation of multiple cells, mainly through the activation of the mitochondrial respiratory chain and initiation of cellular signaling. In addition, it increases the gene expression and protein synthesis of TNF- $\alpha$, IL- 6 , and IL-8 to treat RIOM (63). In a study of 39 patients treated for HNC with different protocols of laser phototherapy, the results showed that using a low-power laser alone or in association with a high-power laser when applied three times a week not only maintained RIOM at grades I or II, but also prevented an increase in the nociceptive reaction (64). Maiya et al. (65) treated RIOM patients using a low-level HeNe laser (wavelength $632.8 \mathrm{~nm}$ and output of $10 \mathrm{~mW}$ ) and found that the mean pain level and mucositis grade were significantly lower in the study group than in the control group $(P<0.001)$. 
TABLE 2 | Clinical trials of various treatments in RIOM.

\begin{tabular}{|c|c|c|c|c|c|c|}
\hline No. & Reference & $\begin{array}{l}\text { Sample } \\
\text { size }\end{array}$ & Treatment method & Evaluation criteria & Design & Result \\
\hline 1 & $\begin{array}{l}\text { Sahebjamee et al. } \\
(67)\end{array}$ & 26 & $\begin{array}{l}\text { Aloe vera mouthwash vs. } \\
\text { benzydamine mouthwash }\end{array}$ & $\begin{array}{l}\geq \text { Grade I RIOM development } \\
\text { time }\end{array}$ & RCT, observational & Similar RIOM severity. \\
\hline 2 & Sayed et al. (68) & 60 & Pentoxifylline and vitamin E & $\geq$ Grade III RIOM incidence & Prospective, observational & $\begin{array}{l}\text { Decreased the duration of } \\
\text { RIOM. }\end{array}$ \\
\hline 3 & Bonfili et al. (69) & 80 & Platelet gel supernatant & $\geq$ Grade III RIOM incidence & RCT, observational & $\begin{array}{l}\text { Decreased the incidence of } \\
\text { WHO grade 3/4 RIOM: } 13 \%\end{array}$ \\
\hline 4 & Soares et al. (70) & 42 & $\begin{array}{l}\text { LLLT (660 and 808-nm } \\
\text { wavelengths vs. only 660-nm } \\
\text { wavelength) }\end{array}$ & $\geq$ Grade I RIOM incidence & $\begin{array}{l}\text { Parallel, single-blind, two-arm } \\
\text { controlled, observational }\end{array}$ & $\begin{array}{l}\text { Group } 1 \text { reduced RIOM grade } \\
\text { in comparison to Group } 2 .\end{array}$ \\
\hline 5 & Huang et al. (71) & 71 & Oral glutamine vs. placebo & RIOM incidence and severity & $\begin{array}{l}\text { Randomized double-blind; } \\
\text { Phase III trial }\end{array}$ & $\begin{array}{l}\text { Glutamine had no effect on } \\
\text { the severity of RIOM. ( } P= \\
0.169)\end{array}$ \\
\hline 6 & Ueno et al. (72) & 97 & $\begin{array}{l}\text { Placebo vs. rebamipide } 2 \% \\
\text { vs. rebamipide } 4 \%\end{array}$ & $\geq$ Grade III RIOM incidence & $\begin{array}{l}\text { Multicenter, randomized, } \\
\text { double-blind, } \\
\text { placebo-controlled, } \\
\text { dose-ranging, phase II trial }\end{array}$ & $\begin{array}{l}\text { The incidences of severe } \\
\text { RIOM: } 39 \text { vs. } 29 \text { vs. } 25 \% \text {. }\end{array}$ \\
\hline 7 & $\begin{array}{l}\text { Santos Filho et al. } \\
\text { (73) }\end{array}$ & 20 & $\begin{array}{l}\text { FITOPROT (curcuminoids plus } \\
\text { Bidens pilosa Linn) }\end{array}$ & $\begin{array}{l}\text { Adverse reactions } \\
\text { development }\end{array}$ & Phase I trail & $\begin{array}{l}\text { FITOPROT was safe and } \\
\text { tolerable for RIOM patients. }\end{array}$ \\
\hline 8 & Kawashita et al. (74) & 124 & $\begin{array}{l}\text { Pilocarpine hydrochloride, } \\
\text { topical dexamethasone } \\
\text { ointment }\end{array}$ & $\geq$ Grade III RIOM incidence & $\begin{array}{l}\text { Multicenter, phase II, } \\
\text { randomized controlled }\end{array}$ & $\begin{array}{l}\text { Decreased incidence of } \\
\text { severe RIOM ( } P=0.046) \text {. }\end{array}$ \\
\hline 9 & $\begin{array}{l}\text { Ribeiro da Silva et al. } \\
(75)\end{array}$ & 29 & PDT vs. LLLT & $\begin{array}{l}\text { The number of clinical cures } \\
\text { of RIOM }\end{array}$ & $\begin{array}{l}\text { Open, controlled, and blind, } \\
\text { randomized; observational }\end{array}$ & $\begin{array}{l}\text { Satisfactory results in } \\
\text { reducing pain. }\end{array}$ \\
\hline 10 & Hadjieva et al. (76) & 38 & CAM2028-benzydamine & Pain intensity & $\begin{array}{l}\text { Observational, Crossover; } \\
\text { double-blind; controlled; } \\
\text { single-dose; randomized }\end{array}$ & Relieve pain effectively. \\
\hline 11 & Giralt et al. (77) & 183 & Clonidine vs. placebo & $\begin{array}{l}\geq \text { Grade III RIOM development } \\
\text { time }\end{array}$ & Phase II, randomized & $\begin{array}{l}\text { RIOM developed in } 45 \text { vs. } \\
60 \%(P=0.06)\end{array}$ \\
\hline 12 & Anderson et al. (78) & 223 & $\begin{array}{l}\text { GC4419 (a superoxide } \\
\text { dismutase mimetic) }\end{array}$ & $\begin{array}{l}\geq \text { Grade III RIOM development } \\
\text { duration }\end{array}$ & $\begin{array}{l}\text { Phase Ilb, Randomized, } \\
\text { Double-Blind }\end{array}$ & $\begin{array}{l}90 \text { mg produced a reduction } \\
\text { of RIOM duration, incidence, } \\
\text { and severity. }\end{array}$ \\
\hline 13 & Legouté et al. (79) & 97 & LLLT & $\begin{array}{l}\geq \text { Grade III RIOM incidence } \\
\text { and time }\end{array}$ & Phase III & $\begin{array}{l}95 \% \text { of patients exhibited a } \\
\text { very good tolerance of LLLT. }\end{array}$ \\
\hline 14 & Sio et al. (80) & 275 & $\begin{array}{l}\text { diphenhydramine-lidocaine- } \\
\text { antacid } \\
\text { mouthwash }\end{array}$ & $\begin{array}{l}\text { RIOM pain reduction during } \\
\text { the } 4 \mathrm{~h}\end{array}$ & Phase III, randomized & $\begin{array}{l}\text { Deduced pain during the first } \\
4 \mathrm{~h} \text { after administration. }\end{array}$ \\
\hline 15 & Hua et al. (81) & 56 & $\mathrm{CRO}$ & Total dose of CRO & Observational, prospective & $\begin{array}{l}\text { Early introduction of CRO may } \\
\text { reduce the total dose of CRO. }\end{array}$ \\
\hline 16 & Jiang et al. (82) & 99 & Probiotic combination & $\geq$ Grade III RIOM incidence & $\begin{array}{l}\text { Randomized, double-blind, } \\
\text { placebo-controlled }\end{array}$ & $\begin{array}{l}\text { The incidences of grade } 3 \\
\text { RIOM was } 15.52 \% \text {. }\end{array}$ \\
\hline 17 & Wu et al. (83) & 156 & Actovegin & $\begin{array}{l}\text { Grade III RIOM incidence and } \\
\text { onset time }\end{array}$ & $\begin{array}{l}\text { Multi-center prospective, } \\
\text { randomized, multi-center }\end{array}$ & $\begin{array}{l}\text { A low progression rate from } \\
\text { grade } 2 \text { to } 3(39.2 \%)\end{array}$ \\
\hline 18 & $\begin{array}{l}\text { Marín-Conde et al. } \\
\text { (84) }\end{array}$ & 26 & LLLT & RIOM incidence and severity & $\begin{array}{l}\text { Prospective randomized } \\
\text { controlled }\end{array}$ & $\begin{array}{l}72.7 \% \text { of the LLLT group } \\
\text { showed normal mucosa. }\end{array}$ \\
\hline 19 & Onseng et al. (85) & 39 & Melatonin vs. placebo & Incidence and time to grade III & $\begin{array}{l}\text { Randomized, double-blind, } \\
\text { double dummy, } \\
\text { placebo-controlled }\end{array}$ & $\begin{array}{l}\text { Incidence of grade } 3 \text { RIOM: } \\
42 \% \text {. }\end{array}$ \\
\hline 20 & Gautam et al. (2) & 46 & $\operatorname{LLLT}(\lambda=632.8 \mathrm{~nm})$ & RIOM incidence and duration & $\begin{array}{l}\text { Double blinded, randomized, } \\
\text { lacebo controlled }\end{array}$ & $\begin{array}{l}\text { Reduce the incidence and } \\
\text { duration of severe RIOM. }\end{array}$ \\
\hline
\end{tabular}

RIOM, radiation-induced oral mucositis; LLLT, low-level laser therapy; PDT, photodynamic therapy; CRO, controlled-release oxycodone.

Bensadoun et al. (66) reported a similar study and found that Grade III mucositis occurred in $35.2 \%$ of those treated without a low-energy He-Ne laser and 7.6\% of those treated with an LEL$60 \mathrm{~mW}$, wavelength $632.8 \mathrm{~nm}(P<0.01)$. These HNC patients received $\mathrm{He}-\mathrm{Ne}$ laser applications daily for 5 consecutive days
(Monday to Friday) each week during the 7 weeks of RT, before the radiation sessions. Moreover, pain relief was significantly better throughout the treatment period (weeks 2-7). In summary, nearly all studies showed good results with reductions in both the incidence and severity of RIOM with no adverse effects, and LLLT 
can reduce the duration of RIOM to relieve pain. This article summarizes the results of some clinical trials for the treatment of RIOM in Table 2. Most of these studies are comparative experiments and consider the time and incidence of RIOM as the primary endpoint, to judge the efficacy of one or more drugs.

\section{PREVENTIVE MEASURES Oral Care}

Oral care is an important integrated prevention strategy for RIOM. The salivary glands do not produce saliva because of radiation damage. The oral cavity gradually becomes acidic, which in turn causes a large number of fungi to multiply. Proper oral care makes the mouth alkaline, reducing the incidence of RIOM. Oral care includes mechanical cleaning (tooth brushing and flossing) and the use of mouthwashes to reduce bacterial aggregation, as well as hydration and lubrication of the oral mucosal surface. It is important to maintain a clean oral cavity through regular brushing, flossing, rinsing, and moisturizing, which can reduce the possibility of oral infection and minimize mucosal tissue injury. Alkalinizing mouthwash is the most frequently used mouthwash for preventing RIOM. The occurrence of RIOM is delayed in HNC patients who undertake continuous oral rinsing for more than 1 month (86). Dodd et al. (87) revealed no significant difference between the efficacy of micronized sucralfate mouthwash and salt and soda mouthwash (86). Alkalinizing mouthwash is the most frequently used mouthwash for preventing RIOM. A randomized controlled trial was conducted to compare the efficacy of an aloe vera mouthwash with that of a benzydamine mouthwash. This revealed that there was no difference between the two groups; thus, an aloe vera mouthwash could be an alternative agent in the prevention of RIOM (67). Kazemian et al. (88) had made a randomized trial that subjects were to rinse with $15 \mathrm{~mL}$ benzydamine or placebo for $2 \mathrm{~min}, 4$ times a day from the 1 st day of RT to the end, and found that in the benzydamine group, the incidence rate of RIOM grade $\geq 3$ in $\mathrm{HNC}$ patients was $43.6 \%$, in contrast to a rate of $78.6 \%$ in the placebo group ( $P=$ 0.001 ). This trial demonstrated positive effects of benzydamine oral rinse in prevention of RIOM. Saarilahti et al. (89) compared GM-CSF mouthwashes consisting 37.5 microg GM-CSF with sucralfate mouthwashes consisting $1.0 \mathrm{~g}$ of sucralfate distilled in water in the prevention of RIOM. This research reported that oral mucositis tended to be less severe in the GM-CSF group ( $p=$ 0.072), and deduced that the use of GM-CSF mouthwashes may lead to less frequent RT course interruptions from mucositis.

\section{Nutritional Support}

Malnutrition is a common problem among patients with HNC, and $3-52 \%$ of HNC patients develop malnutrition without RT (90). During RT, $44 \%$ of HNC patients develop malnutrition (91). In addition, $88 \%$ of HNC patients develop malnutrition during CCRT (92). Application of local anesthetics before food consumption and using preferably liquid/semisolid foods with high calorie and protein content may be possible approaches (55). Experts have suggested that patients with RIOM should avoid smoking, alcohol, and certain foods, such as tomatoes, citrus fruits, and spicy foods (39). Acidic foods and hot dishes can aggravate RIOM, thus avoiding spicy food can limit any injury to the oral mucosa (39). Positive nutritional support will enhance oral mucosal resistance, reduce the chance of infection, and promote the repair of RIOM. Goda et al. (93) evaluated the efficacy of percutaneous endoscopic gastrostomy (PEG). They suggested that therapeutic PEG is useful for preventing the interruption of RT in HNC patients and should be performed before the radiation therapy dose reaches $30 \mathrm{~Gy}$ to avoid severe mucositis. Yamazaki et al. (94) conducted a study and found that the incidence of Grade III or IV oral mucositis was lower in patients receiving PEG than in those who did not receive PEG. In a word, early prophylactic PEG can reduce the occurrence of severe adverse reactions (mucositis and weight loss) and avoid RT interruption. In addition, the timing of nutritional intervention will also affect the incidence and severity of RIOM. A lot of literatures reported that early nutritional intervention would be beneficial to the treatment of HNC patients and reduce the occurrence of adverse reactions. Meng et al. (95) randomly divided a cohort of $78 \mathrm{HNC}$ patients into early $(n=$ $46)$ and late $(n=32)$ nutrition intervention groups. The early group of patients received nutritional support at the beginning of CRT, whereas the late group received such a support until development of the side effects. And they found that the early group showed a lower rate of advanced RIOM $(p<0.05)$. Similarly, Wei et al. (96) made a trial to compare early ( $n$ $=28)$ and late $(n=26)$ nutrition intervention groups. The early group received enteral nutrition at the beginning of RT, while the late group received enteral nutrition after restricted feeding. And they clarified that the incidence of high-grade RIOM was significantly lower in the early group than that in the late group $(P<0.05)$. In a word, HNC patients suffer malnutrition early and worsened continuously during RT, so it is important for patients to receive early nutritional support at the beginning of RT, especially in patients at high grade of RIOM (97).

\section{Radiation Regimen}

The severity of RIOM varies with the RT regimen. In recent years, RT technology has become increasingly more advanced for HNC patients with the aim of protecting the oral mucosa, leading to the development of approaches such as IMRT and volumetric modulated arc therapy. Bjarnason et al. (98) compared two groups: morning RT vs. afternoon RT. They revealed a significant reduction in Grade III or greater mucositis in the morning RT group ( 44.6 vs. $67.3 \%, P=0.022$ ); morning RT also prolonged the interval until RIOM development (median, $>7.9$ vs. 5.6 weeks, $P=0.033$ ). Dean et al. (99) generated predictive models of severe acute mucositis using RT dose and clinical data. They concluded that receiving intermediate and high doses of oral volume may increase the incidence of mucositis.

\section{Oral Cryotherapy}

Oral cryotherapy offers a convenient and non-invasive prophylactic option for preventing oral mucositis (OM). Riley et al. (100) concluded that oral cryotherapy is effective 
TABLE 3 | Clinical trials of various preventions in RIOM.

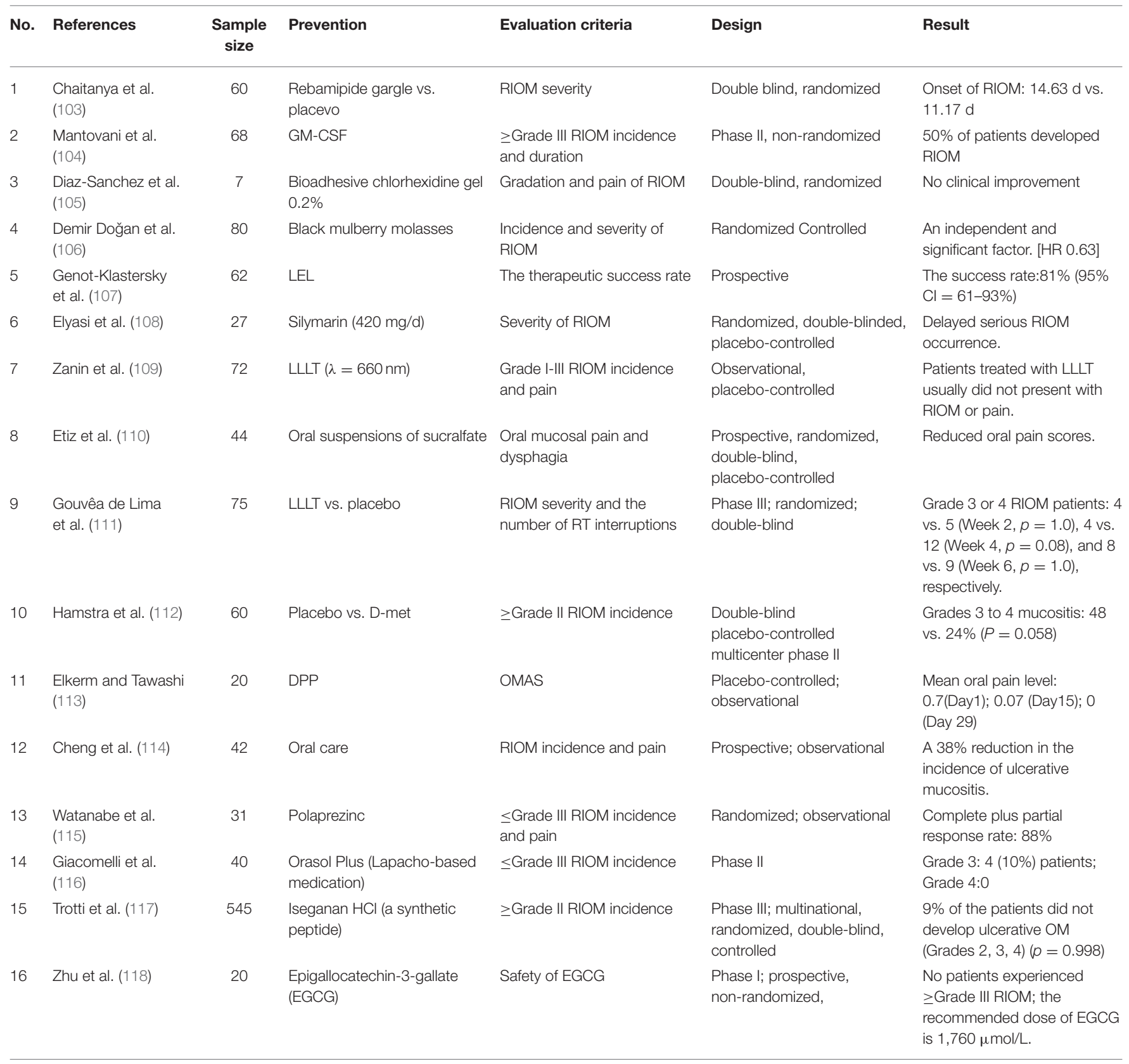

RIOM, radiation-induced oral mucositis; GM-CSF, granulocyte-macrophage colony stimulating factor; $\mathrm{HR}$, hazard ratio; Cl, confidence interval; CCRT, concurrent chemoradiation therapy; LLLT, low-level laser therapy; Low-energy laser, LEL; D-met; D-methionine; DPP, date palm pollen; OMAS, Oral Mucositis Assessment Scale.

for the prevention of $\mathrm{OM}$ in patients receiving fluorouracilbased chemotherapy. Redding (101) inferred that putting ice chips in the mouth 5 min before administering a 5-FU bolus injection and continuing to do so for $30 \mathrm{~min}$ would cool the oral cavity and lead to vasoconstriction. This hypothesis had been certified in a research published in 1991 (102). Patients was randomized divided into two groups, one group received oral cryotherapy during chemotherapy, and the other group served as control group. And they found that $\mathrm{OM}$ was reduced by $\sim 50 \%$ in the group receiving oral cryotherapy, compared to the control group. Oral cryotherapy is frequently applied in chemotherapy-induced OM, and it has a good preventive effect. But it has not been reported and applied in RIOM. The results of some clinical trials for the prevention of RIOM are summarized in Table 3, excluding retrospective experiments. Most of them consider the incidence and severity of RIOM as the observation standard to judge the effect of different prevention schemes. 


\section{DISCUSSION}

RIOM is a common complication in patients with HNC after RT. The main clinical symptoms are oral pain, mucosal ulcers, and dysphagia. Currently, there are numerous prevention and treatment strategies for RIOM. Good oral health, adequate nutritional support, and advanced RT approaches can prevent RIOM. In addition, RIOM treatment focuses on reducing symptoms and complications. The treatment regimens include analgesic and anti-inflammatory drugs, medications and LLLT. For grade I and II RIOM, the treatments are mainly concerned with oral care, especially postprandial oral cleaning, mouthwash with saline and nutritional support. Apart from those, patients can also use mucosal protective agents. For grade III-IV RIOM, in addition to the treatment measures of grade I-II, patients can also add anti-inflammatory drugs and hormones. And we need to pay attention to the management of pain, adding different analgesics according to the level of pain. In addition, LLLT can also be considered to use for patients. However, at present, for the prevention and treatment of radiation-induced mucosal injury, the medical community has not yet formed any standardized medical nutrition treatment program, and the mechanism of mucosal injury remains to be thoroughly studied.

\section{REFERENCES}

1. Hegde JV, Demanes DJ, Veruttipong D, Chin RK, Park SJ, Kamrava M. Head and neck cancer reirradiation with interstitial high-dose-rate brachytherapy. Head Neck. (2018) 40:1524-33. doi: 10.1002/hed.25137

2. Gautam AP, Fernandes DJ, Vidyasagar MS, Maiya AG, Guddattu V. Low level laser therapy against radiation induced oral mucositis in elderly head and neck cancer patients-a randomized placebo controlled trial. J Photochem Photobiol B. (2015) 144:51-6. doi: 10.1016/j.jphotobiol.2015.01.011

3. Moslemi D, Nokhandani AM, Otaghsaraei MT, Moghadamnia Y, Kazemi S, Moghadamnia AA. Management of chemo/radiation-induced oral mucositis in patients with head and neck cancer: a review of the current literature. Radiother Oncol. (2016) 120:13-20. doi: 10.1016/j.radonc.2016. 04.001

4. Elting LS, Cooksley CD, Chambers MS, Garden AS. Risk, outcomes, and costs of radiation-induced oral mucositis among patients with headand-neck malignancies. Int J Radiat Oncol Biol Phys. (2007) 68:1110-20. doi: 10.1016/j.ijrobp.2007.01.053

5. Vera-Llonch M, Oster G, Hagiwara M, Sonis S. Oral mucositis in patients undergoing radiation treatment for head and neck carcinoma. Cancer. (2006) 106:329-36. doi: 10.1002/cncr.21622

6. Sonis ST. Mucositis: the impact, biology and therapeutic opportunities of oral mucositis. Oral Oncol. (2009) 45:1015-20. doi: 10.1016/j.oraloncology.2009.08.006

7. Barasch A, Peterson DE. Risk factors for ulcerative oral mucositis in cancer patients: unanswered questions. Oral Oncol. (2003) 39:91-100. doi: 10.1016/s1368-8375(02)00033-7

8. Chen SC, Lai YH, Huang BS, Lin CY, Fan KH, Chang JT. Changes and predictors of radiation-induced oral mucositis in patients with oral cavity cancer during active treatment. Eur J Oncol Nurs. (2015) 19:214-9. doi: 10.1016/j.ejon.2014.12.001

9. Chen L, Hu CS, Chen XZ, Hu GQ, Cheng ZB, Sun Y, et al. Concurrent chemoradiotherapy plus adjuvant chemotherapy versus concurrent chemoradiotherapy alone in patients with locoregionally advanced nasopharyngeal carcinoma: a phase 3 multicentre randomised controlled trial. Lancet Oncol. (2012) 13:163-71. doi: 10.1016/s1470-2045(11)70320-5

\section{AUTHOR CONTRIBUTIONS}

XJ and LD: conceptualization. QZ and ZL: software and investigation. ZZ: resources. SL and QZ: writing-original draft preparation. $\mathrm{LM}, \mathrm{LD}$, and $\mathrm{XJ}$ : writing-review and editing. XJ: funding acquisition. All authors read and approved the manuscript.

\section{FUNDING}

This work was supported by the National Natural Science Foundation of China (Grant No. 81570344); National Key R\&D Program of China (Grant No. 2017YFC0112100); the Education Department Foundation of Jilin Province (Grant No. JJKH20201036KJ); the Health and Family Planning Commission of Jilin Province Foundations (Grant Nos. 2016Q034 and 2017J11) and the Jilin Provincial Science and Technology Foundations (Grant Nos. 20180414039GH and 20190201200JC).

\section{ACKNOWLEDGMENTS}

We would like to thank Editage (www.editage.cn) for English language editing.

10. Trotti A, Bellm LA, Epstein JB, Frame D, Fuchs HJ, Gwede CK, et al. Mucositis incidence, severity and associated outcomes in patients with head and neck cancer receiving radiotherapy with or without chemotherapy: a systematic literature review. Radiother Oncol. (2003) 66:253-62. doi: 10.1016/s0167-8140(02)00404-8

11. Hsiung CY, Ting HM, Huang HY, Lee CH, Huang EY, Hsu HC. Parotidsparing intensity-modulated radiotherapy (IMRT) for nasopharyngeal carcinoma: preserved parotid function after IMRT on quantitative salivary scintigraphy, and comparison with historical data after conventional radiotherapy. Int J Radiat Oncol Biol Phys. (2006) 66:454-61. doi: 10.1016/j.ijrobp.2006.04.033

12. Romesser PB, Cahlon O, Scher E, Zhou Y, Berry SL, Rybkin A, et al. Proton beam radiation therapy results in significantly reduced toxicity compared with intensity-modulated radiation therapy for head and neck tumors that require ipsilateral radiation. Radiother Oncol. (2016) 118:286-92. doi: 10.1016/j.radonc.2015.12.008

13. Narayan S, Lehmann J, Coleman MA, Vaughan A, Yang CC, Enepekides $D$, et al. Prospective evaluation to establish a dose response for clinical oral mucositis in patients undergoing head-and-neck conformal radiotherapy. Int $J$ Radiat Oncol Biol Phys. (2008) 72:756-62. doi: 10.1016/j.ijrobp.2008.01.060

14. Wang ZH, Zhang SZ, Zhang ZY, Zhang CP, Hu HS, Tu WY, et al. Protecting the oral mucosa in patients with oral tongue squamous cell carcinoma treated postoperatively with intensity-modulated radiotherapy: a randomized study. Laryngoscope. (2012) 122:291-8. doi: 10.1002/lary.22434

15. Xu T, Liu Y, Dou S, Li F, Guan X, Zhu G. Weekly cetuximab concurrent with IMRT aggravated radiation-induced oral mucositis in locally advanced nasopharyngeal carcinoma: results of a randomized phase II study. Oral Oncol. (2015) 51:875-9. doi: 10.1016/j.oraloncology.2015.06.008

16. Li Y, Chen QY, Tang LQ, Liu LT, Guo SS, Guo L, et al. Concurrent chemoradiotherapy with or without cetuximab for stage II to IVb nasopharyngeal carcinoma: a case-control study. BMC Cancer. (2017) 17:567. doi: 10.1186/s12885-017-3552-6

17. Bonner JA, Harari PM, Giralt J, Azarnia N, Shin DM, Cohen RB, et al. Radiotherapy plus cetuximab for squamous-cell carcinoma of the head and neck. N Engl J Med. (2006) 354:567-78. doi: 10.1056/NEJMoa053422 
18. Bonner JA, Giralt J, Harari PM, Baselga J, Spencer S, Bell D, et al. Association of human papillomavirus and p16 status with mucositis and dysphagia for head and neck cancer patients treated with radiotherapy with or without cetuximab: assessment from a phase 3 registration trial. Eur J Cancer. (2016) 64:1-11. doi: 10.1016/j.ejca.2016.05.008

19. Bonner JA, Harari PM, Giralt J, Cohen RB, Jones CU, Sur RK, et al. Radiotherapy plus cetuximab for locoregionally advanced head and neck cancer: 5 -year survival data from a phase 3 randomised trial, and relation between cetuximab-induced rash and survival. Lancet Oncol. (2010) 11:21-8. doi: 10.1016/s1470-2045(09)70311-0

20. Tejwani A, Wu S, Jia Y, Agulnik M, Millender L, Lacouture ME. Increased risk of high-grade dermatologic toxicities with radiation plus epidermal growth factor receptor inhibitor therapy. Cancer. (2009) 115:1286-99. doi: $10.1002 /$ cncr. 24120

21. Mei M, Chen YH, Meng T, Qu LH, Zhang ZY, Zhang X. Comparative efficacy and safety of radiotherapy/cetuximab versus radiotherapy/chemotherapy for locally advanced head and neck squamous cell carcinoma patients: a systematic review of published, primarily non-randomized, data. Ther $A d v$ Med Oncol. (2020) 12:1758835920975355. doi: 10.1177/1758835920975355

22. Pico JL, Avila-Garavito A, Naccache P. Mucositis: its occurrence, consequences, and treatment in the oncology setting. Oncologist. (1998) 3:446-51.

23. Tak A, Metgud R, Astekar M, Tak M. Micronuclei and other nuclear anomalies in normal human buccal mucosa cells of oral cancer patients undergoing radiotherapy: a field effect. Biotech Histochem. (2014) 89:464-9. doi: 10.3109/10520295.2014.904925

24. Sonis ST. The pathobiology of mucositis. Nat Rev Cancer. (2004) 4:277-84. doi: $10.1038 / \mathrm{nrc1} 1318$

25. Russi EG, Raber-Durlacher JE, Sonis ST. Local and systemic pathogenesis and consequences of regimen-induced inflammatory responses in patients with head and neck cancer receiving chemoradiation. Mediators Inflamm. (2014) 2014:518261. doi: 10.1155/2014/518261

26. Maria OM, Eliopoulos N, Muanza T. Radiation-induced oral mucositis. Front Oncol. (2017) 7:89. doi: 10.3389/fonc.2017.00089

27. Sonis S, Haddad R, Posner M, Watkins B, Fey E, Morgan TV, et al. Gene expression changes in peripheral blood cells provide insight into the biological mechanisms associated with regimen-related toxicities in patients being treated for head and neck cancers. Oral Oncol. (2007) 43:289-300. doi: 10.1016/j.oraloncology.2006.03.014

28. Sonis ST. The biologic role for nuclear factor-kappaB in disease and its potential involvement in mucosal injury associated with anti-neoplastic therapy. Crit Rev Oral Biol Med. (2002) 13:380-9. doi: 10.1177/154411130201300502

29. Criswell T, Leskov K, Miyamoto S, Luo G, Boothman DA. Transcription factors activated in mammalian cells after clinically relevant doses of ionizing radiation. Oncogene. (2003) 22:5813-27. doi: 10.1038/sj.onc. 1206680

30. Davis RJ. Signal transduction by the JNK group of MAP kinases. Cell. (2000) 103:239-52. doi: 10.1016/s0092-8674(00)00116-1

31. Bamba S, Andoh A, Yasui H, Araki Y, Bamba T, Fujiyama Y. Matrix metalloproteinase-3 secretion from human colonic subepithelial myofibroblasts: role of interleukin-17. J Gastroenterol. (2003) 38:548-54. doi: $10.1007 / \mathrm{s} 00535-002-1101-8$

32. Mole RH. Whole body irradiation; radiobiology or medicine? Br J Radiol. (1953) 26:234-41. doi: 10.1259/0007-1285-26-305-234

33. Castellheim A, Brekke OL, Espevik T, Harboe M, Mollnes TE. Innate immune responses to danger signals in systemic inflammatory response syndrome and sepsis. Scand J Immunol. (2009) 69:479-91. doi: $10.1111 / j .1365-3083.2009 .02255 . x$

34. Engels-Deutsch M, Pini A, Yamashita Y, Shibata Y, Haikel Y, SchöllerGuinard $\mathrm{M}$, et al. Insertional inactivation of pac and $\mathrm{rmlB}$ genes reduces the release of tumor necrosis factor alpha, interleukin-6, and interleukin-8 induced by Streptococcus mutans in monocytic, dental pulp, and periodontal ligament cells. Infect Immun. (2003) 71:5169-77. doi: 10.1128/iai.71.9.5169-5177.2003

35. Gruber S, Dörr W. Tissue reactions to ionizing radiation-Oral mucosa. Mutat Res. (2016) 770:292-98. doi: 10.1016/j.mrrev.2016.07.007
36. Sonis ST, Elting LS, Keefe D, Peterson DE, Schubert M, Hauer-Jensen M, et al. Perspectives on cancer therapy-induced mucosal injury: pathogenesis, measurement, epidemiology, and consequences for patients. Cancer. (2004) 100(Suppl. 9):1995-2025. doi: 10.1002/cncr.20162

37. Sonis ST. Oral mucositis. Anticancer Drugs. (2011) 22:607-12. doi: 10.1097/CAD.0b013e3283462086

38. Bourbonne V, Otz J, Bensadoun RJ, Dissaux G, Lucia F, Leclere JC, et al. Radiotherapy mucositis in head and neck cancer: prevention by low-energy surface laser. BMJ Support Palliat Care. (2019). doi: 10.1136/bmjspcare-2019-001851. [Epub ahead of print].

39. Peterson DE, Boers-Doets CB, Bensadoun RJ, Herrstedt J. Management of oral and gastrointestinal mucosal injury: ESMO clinical practice guidelines for diagnosis, treatment, and follow-up. Ann Oncol. (2015) 26(Suppl. 5):v139-51. doi: 10.1093/annonc/mdv202

40. Assessing stomatitis: refinement of the Western Consortium for Cancer Nursing Research (WCCNR) stomatitis staging system. Can Oncol Nurs J. (1998) 8:160-5.

41. Lalla RV, Bowen J, Barasch A, Elting L, Epstein J, Keefe DM, et al. MASCC/ISOO clinical practice guidelines for the management of mucositis secondary to cancer therapy. Cancer. (2014) 120:1453-61. doi: $10.1002 / \mathrm{cncr} .28592$

42. Janjan NA, Weissman DE, Pahule A. Improved pain management with daily nursing intervention during radiation therapy for head and neck carcinoma. Int J Radiat Oncol Biol Phys. (1992) 23:647-52. doi: 10.1016/0360-3016(92)90024-c

43. Kannan V, Bapsy PP, Anantha N, Doval DC, Vaithianathan H, Banumathy $\mathrm{G}$, et al. Efficacy and safety of granulocyte macrophage-colony stimulating factor (GM-CSF) on the frequency and severity of radiation mucositis in patients with head and neck carcinoma. Int J Radiat Oncol Biol Phys. (1997) 37:1005-10. doi: 10.1016/s0360-3016(97)00105-3

44. Henke M, Alfonsi M, Foa P, Giralt J, Bardet E, Cerezo L, et al. Palifermin decreases severe oral mucositis of patients undergoing postoperative radiochemotherapy for head and neck cancer: a randomized, placebo-controlled trial. J Clin Oncol. (2011) 29:2815-20. doi: $10.1200 /$ jco.2010.32.4103

45. Le QT, Kim HE, Schneider CJ, Muraközy G, Skladowski K, Reinisch S, et al. Palifermin reduces severe mucositis in definitive chemoradiotherapy of locally advanced head and neck cancer: a randomized, placebo-controlled study. J Clin Oncol. (2011) 29:2808-14. doi: 10.1200/jco.2010.32.4095

46. Maria OM, Shalaby M, Syme A, Eliopoulos N, Muanza T. Adipose mesenchymal stromal cells minimize and repair radiation-induced oral mucositis. Cytotherapy. (2016) 18:1129-45. doi: 10.1016/j.jcyt.2016. 06.008

47. Wu HG, Song SY, Kim YS, Oh YT, Lee CG, Keum KC, et al. Therapeutic effect of recombinant human epidermal growth factor (RhEGF) on mucositis in patients undergoing radiotherapy, with or without chemotherapy, for head and neck cancer: a double-blind placebo-controlled prospective phase 2 multi-institutional clinical trial. Cancer. (2009) 115:3699-708. doi: $10.1002 /$ cncr. 24414

48. Epstein JB, Silverman S, Paggiarino DA, Crockett S, Schubert MM, Senzer NN, et al. Benzydamine $\mathrm{HCl}$ for prophylaxis of radiationinduced oral mucositis: results from a multicenter, randomized, double-blind, placebo-controlled clinical trial. Cancer. (2001) 92:875-85. doi: 10.1002/1097-0142(20010815)92:4<875::aid-cncr1396>3.0.co;2-1

49. Sheibani KM, Mafi AR, Moghaddam S, Taslimi F, Amiran A, Ameri A. Efficacy of benzydamine oral rinse in prevention and management of radiation-induced oral mucositis: a double-blind placebo-controlled randomized clinical trial. Asia Pac J Clin Oncol. (2015) 11:22-7. doi: $10.1111 /$ ajco.12288

50. KawashitaY, Hayashida S, Funahara M, Umeda M, Saito T. Prophylactic bundle for radiation-induced oral mucositis in oral or oropharyngeal cancer patients. J Cancer Res Ther. (2014) 2:9-13. doi: 10.14312/2052-4994.2014-2

51. Nishii M, Soutome S, Kawakita A, Yutori H, Iwata E, Akashi M, et al. Factors associated with severe oral mucositis and candidiasis in patients undergoing radiotherapy for oral and oropharyngeal carcinomas: a retrospective multicenter study of 326 patients. Support Care Cancer. (2020) 28:1069-75. doi: 10.1007/s00520-019-04885-z 
52. Sun WH, Tsuji S, Tsujii M, Gunawan ES, Kawai N, Kimura A, et al. Induction of cyclooxygenase- 2 in rat gastric mucosa by rebamipide, a mucoprotective agent. J Pharmacol Exp Ther. (2000) 295:447-52.

53. Yasuda T, Chiba H, Satomi T, Matsuo A, Kaneko T, Chikazu D, et al. Preventive effect of rebamipide gargle on chemoradiotherpy-induced oral mucositis in patients with oral cancer: a pilot study. J Oral Maxillofac Res. (2012) 2:e3. doi: 10.5037/jomr.2011.2403

54. Khanal B, Baliga M, Uppal N. Effect of topical honey on limitation of radiation-induced oral mucositis: an intervention study. Int J Oral Maxillofac Surg. (2010) 39:1181-5. doi: 10.1016/j.ijom.2010.05.014

55. Mallick S, Benson R, Rath GK. Radiation induced oral mucositis: a review of current literature on prevention and management. Eur Arch Otorhinolaryngol. (2016) 273:2285-93. doi: 10.1007/s00405-015-3694-6

56. Leyes Borrajo JL, Garcia VL, Lopez CG, Rodriguez-Nuñez I, Garcia FM, Gallas TM. Efficacy of chlorhexidine mouthrinses with and without alcohol: a clinical study. J Periodontol. (2002) 73:317-21. doi: 10.1902/jop.2002.73.3.317

57. Stokman MA, Spijkervet FK, Burlage FR, Dijkstra PU, Manson WL, de Vries EG, et al. Oral mucositis and selective elimination of oral flora in head and neck cancer patients receiving radiotherapy: a double-blind randomised clinical trial. Br J Cancer. (2003) 88:1012-6. doi: 10.1038/sj.bjc.6600824

58. Veness MJ, Foroudi F, Gebski V, Timms I, Sathiyaseelan Y, Cakir B, et al. Use of topical misoprostol to reduce radiation-induced mucositis: results of a randomized, double-blind, placebo-controlled trial. Aust Radiol. (2006) 50:468-74. doi: 10.1111/j.1440-1673.2006.01628.x

59. Bourhis J, De Crevoisier R, Abdulkarim B, Deutsch E, Lusinchi A, Luboinski $\mathrm{B}$, et al. A randomized study of very accelerated radiotherapy with and without amifostine in head and neck squamous cell carcinoma. Int J Radiat Oncol Biol Phys. (2000) 46:1105-8. doi: 10.1016/s0360-3016(99)00532-5

60. Veerasarn V, Phromratanapongse P, Suntornpong N, Lorvidhaya V, Sukthomya V, Chitapanarux I, et al. Effect of amifostine to prevent radiotherapy-induced acute and late toxicity in head and neck cancer patients who had normal or mild impaired salivary gland function. J Med Assoc Thai. (2006) 89:2056-67.

61. Rades D, Fehlauer F, Bajrovic A, Mahlmann B, Richter E, Alberti W. Serious adverse effects of amifostine during radiotherapy in head and neck cancer patients. Radiother Oncol. (2004) 70:261-4. doi: 10.1016/j.radonc.2003.10.005

62. Huang EY, Leung SW, Wang CJ, Chen HC, Sun LM, Fang FM, et al. Oral glutamine to alleviate radiation-induced oral mucositis: a pilot randomized trial. Int J Radiat Oncol Biol Phys. (2000) 46:535-9. doi: 10.1016/s0360-3016(99)00402-2

63. Gao X, Xing D. Molecular mechanisms of cell proliferation induced by low power laser irradiation. J Biomed Sci. (2009) 16:4. doi: 10.1186/1423-0127-16-4

64. Simões A, Eduardo FP, Luiz AC, Campos L, Sá PH, Cristófaro M, et al. Laser phototherapy as topical prophylaxis against head and neck cancer radiotherapy-induced oral mucositis: comparison between low and high/low power lasers. Lasers Surg Med. (2009) 41:264-70. doi: 10.1002/lsm.20758

65. Arun Maiya G, Sagar MS, Fernandes D. Effect of low level helium-neon $(\mathrm{He}-\mathrm{Ne})$ laser therapy in the prevention \& treatment of radiation induced mucositis in head \& neck cancer patients. Indian J Med Res. (2006) 124:399402 .

66. Bensadoun RJ, Franquin JC, Ciais G, Darcourt V, Schubert MM, Viot M, et al. Low-energy $\mathrm{He} / \mathrm{Ne}$ laser in the prevention of radiation-induced mucositis. A multicenter phase III randomized study in patients with head and neck cancer. Support Care Cancer. (1999) 7:244-52. doi: 10.1007/s005200050256

67. Sahebjamee M, Mansourian A, Hajimirzamohammad M, Zadeh MT, Bekhradi R, Kazemian A, et al. Comparative efficacy of aloe vera and benzydamine mouthwashes on radiation-induced oral mucositis: a tripleblind, randomised, controlled clinical trial. Oral Health Prev Dent. (2015) 13:309-15. doi: 10.3290/j.ohpd.a33091

68. Sayed R, El Wakeel L, Saad AS, Kelany M, El-Hamamsy M. Pentoxifylline and vitamin $\mathrm{E}$ reduce the severity of radiotherapy-induced oral mucositis and dysphagia in head and neck cancer patients: a randomized, controlled study. Med Oncol. (2019) 37:8. doi: 10.1007/s12032-019-1334-5

69. Bonfili P, Gravina GL, Marampon F, Rughetti A, Di Staso M, Dell'Orso L, et al. Oral platelet gel supernatant plus supportive medical treatment versus supportive medical treatment in the management of radiation-induced oral mucositis: a matched explorative active control trial by propensity analysis. Am J Clin Oncol. (2017) 40:336-41. doi: 10.1097/coc.0000000000000177

70. Soares RG, Farias LC, da Silva Menezes AS, de Oliveira ESCS, Tabosa ATL, Chagas PVF, et al. Treatment of mucositis with combined 660- and 808-nmwavelength low-level laser therapy reduced mucositis grade, pain, and use of analgesics: a parallel, single-blind, two-arm controlled study. Lasers Med Sci. (2018) 33:1813-19. doi: 10.1007/s10103-018-2549-y

71. Huang CJ, Huang MY, Fang PT, Chen F, Wang YT, Chen CH, et al. Randomized double-blind, placebo-controlled trial evaluating oral glutamine on radiation-induced oral mucositis and dermatitis in head and neck cancer patients. Am J Clin Nutr. (2019) 109:606-14. doi: 10.1093/ajen/nqy329

72. Ueno T, Zenda S, Konishi T, Yurikusa T, Shibasaki Y, Nagamoto H, et al. The post hoc analysis comparing the severity grades of chemoradiotherapyinduced oral mucositis scored between the central and local assessors in a multicenter, randomized controlled trial of rebamipide for head and neck cancer. Int J Clin Oncol. (2019) 24:241-47. doi: 10.1007/s10147-0181355-7

73. Santos Filho EXD, Arantes DAC, Oton Leite AF, Batista AC, Mendonça $\mathrm{EF}$, Marreto RN, et al. Randomized clinical trial of a mucoadhesive formulation containing curcuminoids (Zingiberaceae) and Bidens pilosa Linn (Asteraceae) extract (FITOPROT) for prevention and treatment of oral mucositis - phase I study. Chem Biol Interact. (2018) 291:228-36. doi: 10.1016/j.cbi.2018.06.010

74. Kawashita Y, Koyama Y, Kurita H, Otsuru M, Ota Y, Okura M, et al. Effectiveness of a comprehensive oral management protocol for the prevention of severe oral mucositis in patients receiving radiotherapy with or without chemotherapy for oral cancer: a multicentre, phase II, randomized controlled trial. Int J Oral Maxillofac Surg. (2019) 48:857-64. doi: 10.1016/j.ijom.2018.10.010

75. Ribeiro da Silva VC, da Motta Silveira FM, Barbosa Monteiro MG, da Cruz MMD, Caldas Júnior AF, Pina Godoy G. Photodynamic therapy for treatment of oral mucositis: pilot study with pediatric patients undergoing chemotherapy. Photodiagnosis Photodyn Ther. (2018) 21:115-20. doi: 10.1016/j.pdpdt.2017.11.010

76. Hadjieva T, Cavallin-Ståhl E, Linden M, Tiberg F. Treatment of oral mucositis pain following radiation therapy for head-and-neck cancer using a bioadhesive barrier-forming lipid solution. Support Care Cancer. (2014) 22:1557-62. doi: 10.1007/s00520-014-2117-3

77. Giralt J, Tao Y, Kortmann RD, Zasadny X, Contreras-Martinez J, Ceruse $\mathrm{P}$, et al. Randomized phase 2 trial of a novel clonidine mucoadhesive buccal tablet for the amelioration of oral mucositis in patients treated with concomitant chemoradiation therapy for head and neck cancer. Int J Radiat Oncol Biol Phys. (2020) 106:320-28. doi: 10.1016/j.ijrobp.2019.10.023

78. Anderson CM, Lee CM, Saunders DP, Curtis A, Dunlap N, Nangia C, et al. Phase IIb, randomized, double-blind trial of GC4419 versus placebo to reduce severe oral mucositis due to concurrent radiotherapy and cisplatin for head and neck cancer. J Clin Oncol. (2019) 37:3256-65. doi: $10.1200 /$ jco.19.01507

79. Legouté F, Bensadoun RJ, Seegers V, Pointreau Y, Caron D, Lang P, et al. Lowlevel laser therapy in treatment of chemoradiotherapy-induced mucositis in head and neck cancer: results of a randomised, triple blind, multicentre phase III trial. Radiat Oncol. (2019) 14:83. doi: 10.1186/s13014-019-1292-2

80. Sio TT, Le-Rademacher JG, Leenstra JL, Loprinzi CL, Rine G, Curtis A, et al. Effect of doxepin mouthwash or diphenhydramine-lidocaine-antacid mouthwash vs placebo on radiotherapy-related oral mucositis pain: the alliance A221304 randomized clinical trial. JAMA. (2019) 321:1481-90. doi: 10.1001/jama.2019.3504

81. Hua X, Chen LM, Zhu Q, Hu W, Lin C, Long ZQ, et al. Efficacy of controlledrelease oxycodone for reducing pain due to oral mucositis in nasopharyngeal carcinoma patients treated with concurrent chemoradiotherapy: a prospective clinical trial. Support Care Cancer. (2019) 27:3759-67. doi: 10.1007/s00520-019-4643-5

82. Jiang C, Wang H, Xia C, Dong Q, Chen E, Qiu Y, et al. A randomized, doubleblind, placebo-controlled trial of probiotics to reduce the severity of oral mucositis induced by chemoradiotherapy for patients with nasopharyngeal carcinoma. Cancer. (2019) 125:1081-90. doi: 10.1002/cncr.31907 
83. Wu SX, Cui TT, Zhao C, Pan JJ, Xu BY, Tian Y, et al. A prospective, randomized, multi-center trial to investigate actovegin in prevention and treatment of acute oral mucositis caused by chemoradiotherapy for nasopharyngeal carcinoma. Radiother Oncol. (2010) 97:113-8. doi: 10.1016/j.radonc.2010.08.003

84. Marín-Conde F, Castellanos-Cosano L, Pachón-Ibañez J, Serrera-Figallo MA, Gutiérrez-Pérez JL, Torres-Lagares D. Photobiomodulation with lowlevel laser therapy reduces oral mucositis caused by head and neck radiochemotherapy: prospective randomized controlled trial. Int J Oral Maxillofac Surg. (2019) 48:917-23. doi: 10.1016/j.ijom.2018.12.006

85. Onseng K, Johns NP, Khuayjarernpanishk T, Subongkot S, Priprem A, Hurst $C$, et al. Beneficial effects of adjuvant melatonin in minimizing oral mucositis complications in head and neck cancer patients receiving concurrent chemoradiation. J Altern Complement Med. (2017) 23:957-63. doi: 10.1089/acm.2017.0081

86. McGuire DB, Fulton JS, Park J, Brown CG, Correa ME, Eilers J, et al. Systematic review of basic oral care for the management of oral mucositis in cancer patients. Support Care Cancer. (2013) 21:3165-77. doi: 10.1007/s00520-013-1942-0

87. Dodd MJ, Miaskowski C, Greenspan D, MacPhail L, Shih AS, Shiba G, et al. Radiation-induced mucositis: a randomized clinical trial of micronized sucralfate versus salt \& soda mouthwashes. Cancer Invest. (2003) 21:21-33. doi: $10.1081 / \mathrm{cnv}-120016400$

88. Kazemian A, Kamian S, Aghili M, Hashemi FA, Haddad P. Benzydamine for prophylaxis of radiation-induced oral mucositis in head and neck cancers: a double-blind placebo-controlled randomized clinical trial. Eur J Cancer Care. (2009) 18:174-8. doi: 10.1111/j.1365-2354.2008.00943.x

89. Saarilahti K, Kajanti M, Joensuu T, Kouri M, Joensuu H. Comparison of granulocyte-macrophage colony-stimulating factor and sucralfate mouthwashes in the prevention of radiation-induced mucositis: a doubleblind prospective randomized phase III study. Int J Radiat Oncol Biol Phys. (2002) 54:479-85. doi: 10.1016/s0360-3016(02)02935-8

90. Gorenc M, Kozjek NR, Strojan P. Malnutrition and cachexia in patients with head and neck cancer treated with (chemo)radiotherapy. Rep Pract Oncol Radiother. (2015) 20:249-58. doi: 10.1016/j.rpor.2015.03.001

91. Langius JA, Doornaert P, Spreeuwenberg MD, Langendijk JA, Leemans CR, van Bokhorst-de van der Schueren MA. Radiotherapy on the neck nodes predicts severe weight loss in patients with early stage laryngeal cancer. Radiother Oncol. (2010) 97:80-5. doi: 10.1016/j.radonc.2010.02.017

92. Unsal D, Mentes B, Akmansu M, Uner A, Oguz M, Pak Y. Evaluation of nutritional status in cancer patients receiving radiotherapy: a prospective study. Am J Clin Oncol. (2006) 29:183-8. doi: 10.1097/01.coc.0000198745.94757.ee

93. Goda M, Jinnouchi O, Takaoka T, Abe K, Tamura K, Nakaya Y, et al. Efficacy of percutaneous endoscopic gastrostomy on unplanned treatment interruption and nutritional status in patients undergoing chemoradiotherapy for advanced head and neck cancer. J Med Invest. (2015) 62:173-6. doi: 10.2152/jmi.62.173

94. Yamazaki T, Enokida T, Wakasugi T, Zenda S, Motegi A, Arahira S, et al. Impact of prophylactic percutaneous endoscopic gastrostomy tube placement on treatment tolerance in head and neck cancer patients treated with cetuximab plus radiation. Jpn J Clin Oncol. (2016) 46:825-31. doi: 10.1093/jjco/hyw079

95. Meng L, Wei J, Ji R, Wang B, Xu X, Xin Y, et al. Effect of early nutrition intervention on advanced nasopharyngeal carcinoma patients receiving chemoradiotherapy. J Cancer. (2019) 10:3650-56. doi: 10.7150/jca.33475

96. Wei J, Wu J, Meng L, Zhu B, Wang H, Xin Y, et al. Effects of early nutritional intervention on oral mucositis in patients with radiotherapy for head and neck cancer. QJM. (2020) 113:37-42. doi: 10.1093/qjmed/hcz222

97. Shu Z, Zeng Z, Yu B, Huang S, Hua Y, Jin T, et al. Nutritional status and its association with radiation-induced oral mucositis in patients with nasopharyngeal carcinoma during radiotherapy: a prospective study. Front Oncol. (2020) 10:594687. doi: 10.3389/fonc.2020.594687

98. Bjarnason GA, Mackenzie RG, Nabid A, Hodson ID, El-Sayed S, Grimard $\mathrm{L}$, et al. Comparison of toxicity associated with early morning versus late afternoon radiotherapy in patients with head-and-neck cancer: a prospective randomized trial of the National Cancer Institute of Canada Clinical
Trials Group (HN3). Int J Radiat Oncol Biol Phys. (2009) 73:166-72. doi: 10.1016/j.ijrobp.2008.07.009

99. Dean JA, Wong KH, Welsh LC, Jones AB, Schick U, Newbold KL, et al. Normal tissue complication probability (NTCP) modelling using spatial dose metrics and machine learning methods for severe acute oral mucositis resulting from head and neck radiotherapy. Radiother Oncol. (2016) 120:217. doi: 10.1016/j.radonc.2016.05.015

100. Riley P, McCabe MG, Glenny AM. Oral cryotherapy for preventing oral mucositis in patients receiving cancer treatment. JAMA Oncol. (2016) 2:1365-66. doi: 10.1001/jamaoncol.2016.2680

101. Redding SW. Oral complications of cancer therapy. Tex Med. (2003) 99:54-7.

102. Mahood DJ, Dose AM, Loprinzi CL, Veeder MH, Athmann LM, Therneau TM, et al. Inhibition of fluorouracil-induced stomatitis by oral cryotherapy. J Clin Oncol. (1991) 9:449-52. doi: 10.1200/jco.1991.9.3.449

103. Chaitanya B, Pai KM, Yathiraj PH, Fernandes D, Chhaparwal Y. Rebamipide gargle in preventive management of chemoradiotherapy induced oral mucositis. Oral Oncol. (2017) 72:179-82. doi: 10.1016/j.oraloncology.2017.07.024

104. Mantovani G, Massa E, Astara G, Murgia V, Gramignano G, Lusso MR, et al. Phase II clinical trial of local use of GM-CSF for prevention and treatment of chemotherapy- and concomitant chemoradiotherapy-induced severe oral mucositis in advanced head and neck cancer patients: an evaluation of effectiveness, safety and costs. Oncol Rep. (2003) 10:197-206.

105. Diaz-Sanchez RM, Pachón-Ibáñez J, Marín-Conde F, Rodríguez-Caballero Á, Gutierrez-Perez JL, Torres-Lagares D. Double-blind, randomized pilot study of bioadhesive chlorhexidine gel in the prevention and treatment of mucositis induced by chemoradiotherapy of head and neck cancer. Med Oral Patol Oral Cir Bucal. (2015) 20:e378-85. doi: 10.4317/medoral.20338

106. Demir Doǧan M, Can G, Meral R. Effectiveness of black mulberry molasses in prevention of radiotherapy-induced oral mucositis: a randomized controlled study in head and neck cancer patients. J Altern Complement Med. (2017) 23:971-79. doi: 10.1089/acm.2016.0425

107. Genot-Klastersky MT, Klastersky J, Awada F, Awada A, Crombez P, Martinez MD, et al. The use of low-energy laser (LEL) for the prevention of chemotherapy- and/or radiotherapy-induced oral mucositis in cancer patients: results from two prospective studies. Support Care Cancer. (2008) 16:1381-7. doi: 10.1007/s00520-008-0439-8

108. Elyasi S, Hosseini S, Niazi Moghadam MR, Aledavood SA, Karimi G. Effect of oral silymarin administration on prevention of radiotherapy induced mucositis: a randomized, double-blinded, placebo-controlled clinical trial. Phytother Res. (2016) 30:1879-85. doi: 10.1002/ptr.5704

109. Zanin T, Zanin F, Carvalhosa AA, Castro PH, Pacheco MT, Zanin IC, et al. Use of 660-nm diode laser in the prevention and treatment of human oral mucositis induced by radiotherapy and chemotherapy. Photomed Laser Surg. (2010) 28:233-7. doi: 10.1089/pho.2008.2242

110. Etiz D, Erkal HS, Serin M, Küçük B, Hepari A, Elhan AH, et al. Clinical and histopathological evaluation of sucralfate in prevention of oral mucositis induced by radiation therapy in patients with head and neck malignancies. Oral Oncol. (2000) 36:116-20. doi: 10.1016/s1368-8375(99)00075-5

111. Gouvêa de Lima A, Villar RC, de Castro G, Antequera R, Gil E, Rosalmeida $\mathrm{MC}$, et al. Oral mucositis prevention by low-level laser therapy in headand-neck cancer patients undergoing concurrent chemoradiotherapy: a phase III randomized study. Int J Radiat Oncol Biol Phys. (2012) 82:270-5. doi: 10.1016/j.ijrobp.2010.10.012

112. Hamstra DA, Lee KC, Eisbruch A, Sunkara P, Borgonha S, Phillip B, et al. Double-blind placebo-controlled multicenter phase II trial to evaluate Dmethionine in preventing/reducing oral mucositis induced by radiation and chemotherapy for head and neck cancer. Head Neck. (2018) 40:1375-88. doi: 10.1002/hed.25115

113. Elkerm Y, Tawashi R. Date palm pollen as a preventative intervention in radiation- and chemotherapy-induced oral mucositis: a pilot study. Integr Cancer Ther. (2014) 13:468-72. doi: 10.1177/1534735414 547110

114. Cheng KK, Molassiotis A, Chang AM, Wai WC, Cheung SS. Evaluation of an oral care protocol intervention in the prevention of chemotherapy-induced oral mucositis in paediatric cancer patients. Eur J Cancer. (2001) 37:2056-63. doi: 10.1016/s0959-8049(01)00098-3 
115. Watanabe T, Ishihara M, Matsuura K, Mizuta K, Itoh Y. Polaprezinc prevents oral mucositis associated with radiochemotherapy in patients with head and neck cancer. Int J Cancer. (2010) 127:1984-90. doi: 10.1002/ijc.25200

116. Giacomelli I, Scartoni D, Fiammetta M, Baki M, Zei G, Muntoni C, et al. Oral lapacho-based medication: an easy, safe, and feasible support to prevent and/or reduce oral mucositis during radiotherapy for head and neck cancer. Nutr Cancer. (2015) 67:1247-53. doi: 10.1080/01635581.2015.1082114

117. Trotti A, Garden A, Warde P, Symonds P, Langer C, Redman R, et al. A multinational, randomized phase III trial of iseganan $\mathrm{HCl}$ oral solution for reducing the severity of oral mucositis in patients receiving radiotherapy for head-and-neck malignancy. Int J Radiat Oncol Biol Phys. (2004) 58:674-81. doi: 10.1016/s0360-3016(03)01627-4

118. Zhu W, Mei H, Jia L, Zhao H, Li X, Meng X, et al. Epigallocatechin-3-gallate mouthwash protects mucosa from radiation-induced mucositis in head and neck cancer patients: a prospective, non-randomised, phase 1 trial. Invest New Drugs. (2020) 38:1129-36. doi: 10.1007/s10637-019-00871-8

Conflict of Interest: The authors declare that the research was conducted in the absence of any commercial or financial relationships that could be construed as a potential conflict of interest.

Copyright (C) 2021 Liu, Zhao, Zheng, Liu, Meng, Dong and Jiang. This is an openaccess article distributed under the terms of the Creative Commons Attribution License (CC BY). The use, distribution or reproduction in other forums is permitted, provided the original author(s) and the copyright owner(s) are credited and that the original publication in this journal is cited, in accordance with accepted academic practice. No use, distribution or reproduction is permitted which does not comply with these terms. 